\title{
Deep Vein Thrombosis of the Upper Limb: About 6 Cases Collected in Dakar
}

\section{Mouhamadou Bamba Ndiaye ${ }^{1}$, Fatou Aw ${ }^{1}$, Marguerite Téning Diouf ${ }^{1}$, Joseph Salvador Mingou ${ }^{1}$, Simon Antoine Sarr1', Malick Bodiian', Aliou Alassane Ngaidé ${ }^{2}$, Alassane Mbaye ${ }^{2}$, Adama Kane ${ }^{3}$, Maboury Diao' ${ }^{1}$, Abdoul Kane ${ }^{4}$}

${ }^{1}$ Department of Cardiology, Aristide Le Dantec Hospital University, Dakar, Senegal

${ }^{2}$ Department of Cardiology, HOGGY, Dakar, Senegal

${ }^{3}$ Departement of Cardiology, Regional Hospital of Saint Louis, Saint Louis, Senegal

${ }^{4}$ Departement of Cardiology, Dalal Jamm Hospital, Dakar, Senegal

Email: mingoujoseph@gmail.com

How to cite this paper: Ndiaye, M.B., Aw, F., Diouf, M.T., Mingou, J.S., Sarr, S.A., Bodiian, M., Ngaidé, A.A., Mbaye, A., Kane, A., Diao, M. and Kane, A. (2020) Deep Vein Thrombosis of the Upper Limb: About 6 Cases Collected in Dakar. World Journal of Cardiovascular Diseases, 10, 57-66. https://doi.org/10.4236/wjcd.2020.102007

Received: December 21, 2019

Accepted: February 16, 2020

Published: February 19, 2020

Copyright $\odot 2020$ by author(s) and Scientific Research Publishing Inc. This work is licensed under the Creative Commons Attribution International License (CC BY 4.0).

http://creativecommons.org/licenses/by/4.0/

\begin{abstract}
Deep vein thrombosis of the upper limb is a rare location of venous thromboembolic disease. Data on this form of thrombosis are limited. We report six cases collected in Dakar. The sex ratio was 0.5 and the average age was 27.6 years with extremes of 17 and 39. Painful limb edema was the most constant sign and involved the non-dominant limb in almost all patients. Thrombosis occurred in a field of peripartum cardiomyopathy in two patients and SS sickle cell disease in one patient taking oral contraception. There was neither cancer nor venous catheter in medical history. The diagnosis was made by venous Doppler ultrasound in all patients. Subclavian involvement was the most common. The thrombophilia assessment, done for two patients, was normal. It was about exertion thrombosis on three (3) patients. All the patients had received antivitamin $\mathrm{K}$ treatment relaying a low molecular weight heparin. Venous limb compression was associated with anticoagulation for all patients. The treatment duration was six (6) months. There were no reports of pulmonary embolism or death. One patient presented a post-thrombotic syndrome.
\end{abstract}

\section{Keywords}

Deep Vein Thrombosis, Upper Limb, Dakar

\section{Introduction}

Deep vein thrombosis (DVT) of the upper limb is a special form of venous 
thromboembolic disease. Their incidence is difficult to estimate with precision. In recent thromboembolic disease registers, DVT of the upper limb accounts for approximately $5 \%-10 \%$ of cases [1] [2]. The diagnosis of venous thrombosis of the upper limb is primarily clinical. As with the lower limb, the clinical signs of the upper limb thrombosis are related to the obstruction and the resulting inflammation. The venous Doppler ultrasound allowed the diagnosis to be made for all our patients. It specified the location and extent of the thrombosis. It is the first-line diagnostic method in the vast majority of cases. In Sub-Saharan Africa, the published cases [3] [4] show that the incidence of upper limb DVT should increase with the wide use of central venous catheters, endocavitary procedures, and the development of means of diagnostic investigation; hence the interest of a better knowledge of this affection in the black skin subject. Therefore, we report 6 cases observed at the cardiology clinic of the Dantec University Hospital in Dakar.

\section{Methodology}

This was a descriptive cross-sectional study from April 1, 2015 to October 31, 2018. All patients with documented upper limb DVT, confirmed on the upper limbs venous Doppler ultrasound, and hospitalized in the cardiology department during this period were included. Patients with an unusable record were not included.

Collected data concerned:

- socio-demography, namely gender, age, profession and dominant member

- history and field (a field of sickle cell anemia, neoplasia, acquired or congenital coagulopathy, drug addiction of endocavitary maneuvers)

- clinical signs, i.e. the data from the general examination and the devices

- paraclinical signs concerning the results of the venous Doppler ultrasound of the limb and the examinations with etiological aim.

- treatment (type and duration)

- evolutionary modalities (complication such as pulmonary embolism, post-phlebitic disease or recurrence).

Data were collected after an informed consent of all patients.

\section{Results}

During the period from April 1, 2015 to October 31, 2018, we collected 6 patients.

\section{Observation 1}

Mrs. N. K, 26, a housewife, was hospitalized for peripartum cardiomyopathy decompensated by left pneumopathy. This picture was associated with painful edema of the left upper limb, the non-dominant member.

The limb symptomatology dates back to a week before admission, marked by pain and a progressive increase in the volume of the upper limb, from the root of the shoulder to the elbow, extending to the breast. There was no notion of a 
venous catheter, nor any specific history.

The examination found an edema of the limb, an increased local heat and a filling of the supra-clavicular hollow. The left breast was painfully edematous with an erythema. Elsewhere, there was a global heart failure syndrome.

The venous Doppler ultrasound showed a basilic and cephalic thrombosis extended to the axillary, subclavian and jugular veins (Figure 1). Doppler echocardiography found a hypokinetic dilated cardiomyopathy with an ejection fraction of the left ventricle at $20 \%$. The mammogram compared to the breast ultrasound was in favor of mastitis.

A treatment with low molecular weight heparin, overlapped with VKA (acenocoumarol) and associated with venous compression, had been initiated during hospitalization (Table 1). The evolution was favorable with an almost complete regression of the edema and a sedation of the pain. Acenocoumarol was maintained for six months. The patient seen at the check-up, a year later, had no recurrence or developed post-thrombotic syndrome.

Observation 2

Miss C. E, 21, a right-handed computer science student, was admitted for painful edema of the left upper limb.

Symptoms dated back to five days with waking pain, of moderate intensity, located in the arm. There was no concept of trauma or venous catheter. This persistent pain spread to the entire limb, despite the local application of a non-steroidal anti-inflammatory drug, was accompanied by a progressive increase in the limb with relative functional impotence.

The patient had a SS sickle cell and was on progestin-only oral contraception (medroxyprogesterone acetate). The examination showed painful edema of the limb, with no entry point, or axillary lymphadenopathy. Elsewhere, the examination noted a conjunctival sub-jaundice and a pallor.

The biological assessment found a microcytic anemia at $8.5 \mathrm{~g} / \mathrm{dl}$ and a negative retroviral serology. A Doppler ultrasound showed a venous thrombosis extending from the subclavian vein to the brachial vein.

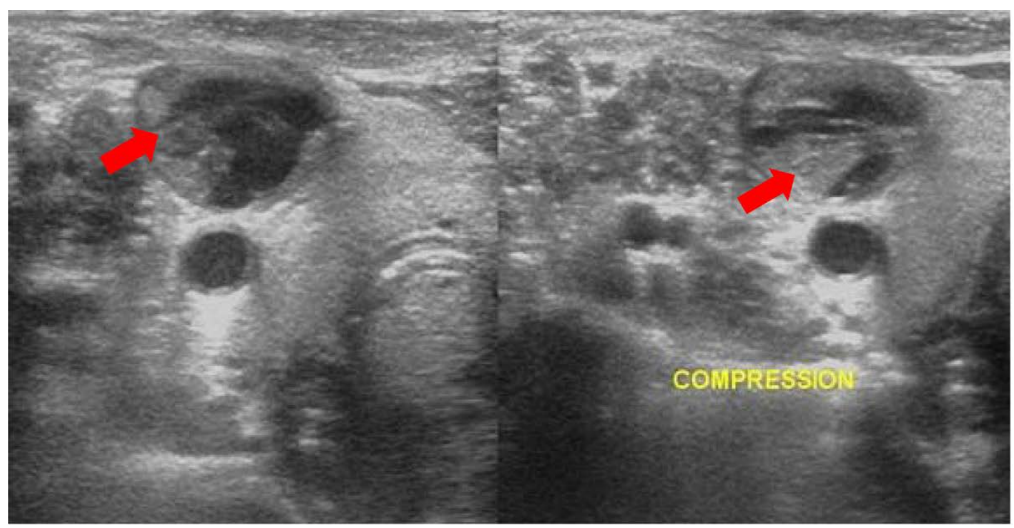

Figure 1. Venous Doppler ultrasound showing a non-compressible dilated right axillary vein, with echogenic content related to the presence of a thrombus [Aristide Le Dantec University Hospital]. 
Table 1. Characteristics of patients.

\begin{tabular}{cccc}
\hline Observation Number & 1 & 2 & 3 \\
\hline Age (years)/sex & $26 / \mathrm{F}$ & $21 / \mathrm{F}$ & $17 / \mathrm{M}$ \\
Past medical history/field & Peripartum cardiomyopathy, Mastitis & $\begin{array}{c}\text { Sickle cell disease SS } \\
\text { Contraception } \\
\text { Clinical signs }\end{array}$ & Painful edema \\
Location & Painful edema & Subclavian, brachial & Painful edema \\
Etiologies & Mammography (-) & Thrombophilia not realized & Thrombophilia (-) \\
Hillary serology (-)
\end{tabular}

LMWH: low molecular weight heparin; VKA: vitamin K antagonists; (-): normal; HIV: Human Immunodeficiency Virus; F: Female; M: Male.

The patient was treated with VKA (acenocoumarol) with a target INR between 2 and 3. A venous compression was associated (Table 1). The clinical signs of thrombosis disappeared within a few days. VKA treatment was continued for six months. At check-up, after nine months, there was no post-thrombotic syndrome and venous Doppler ultrasound was normal.

Observation 3

Mr C. D, 17 years old, pupil, had been received for an inflammatory swelling of the left upper limb, not dominant. The onset began 2 days before admission, marked by painful edema, no fever, no sign of trauma. There was no concept of a venous catheter, nor familial thrombophilia. The patient reported a similar episode 7 months earlier, spontaneously resolving in 2 days.

The physical examination found an enlarged, hot, painful member at the shoulder root. The rest of the exam was unremarkable.

The retroviral serology and the Emmel test were negative. The thrombophilia assessment was normal. Venous Doppler ultrasound showed thrombosis extended to the axillary, basilic and cephalic veins with infiltration of the subcutaneous tissue of the arm and forearm (Figure 1). The thoracic abdominal CT scan was unremarkable. The patient had been admitted with low molecular weight heparin at an overlapping curative dose, then relayed by VKA (acenocoumarol) and associated with venous compression (Table 1). The course was marked by a regression of pain and edema. The examination after one month found a complete regression of the edema, and there was no pain nor collateral venous circulation.

\section{Observation 4}

Mrs. A. C, 38, a housewife, was admitted to our department for decompensated peripartum cardiomyopathy associated with edema of the right upper limb. The symptomatology of the limb dates back to 3 days before admission by a progressive increase in the limb, paresthesia and heaviness. There was no concept of trauma or venous catheter. The examination found edema going from 
the root of the shoulder to the hand, with a $5 \mathrm{~cm}$ difference in measurement between the two members. There was no change in local temperature and the skin was normal. The rest of the examination revealed a syndrome of global heart failure. Doppler ultrasound showed a venous thrombosis extended to the internal jugular, subclavian, axillary, brachial and basilic veins. The patient had been admitted with low molecular weight heparin with an overlapping curative dose, then relayed by VKA (acenocoumarol), associated with venous compression (Table 2).

The course after a few days of anticoagulation was marked by a partial regression of the edema. After one month, we noticed an edema of the hand and forearm (Figure 2).

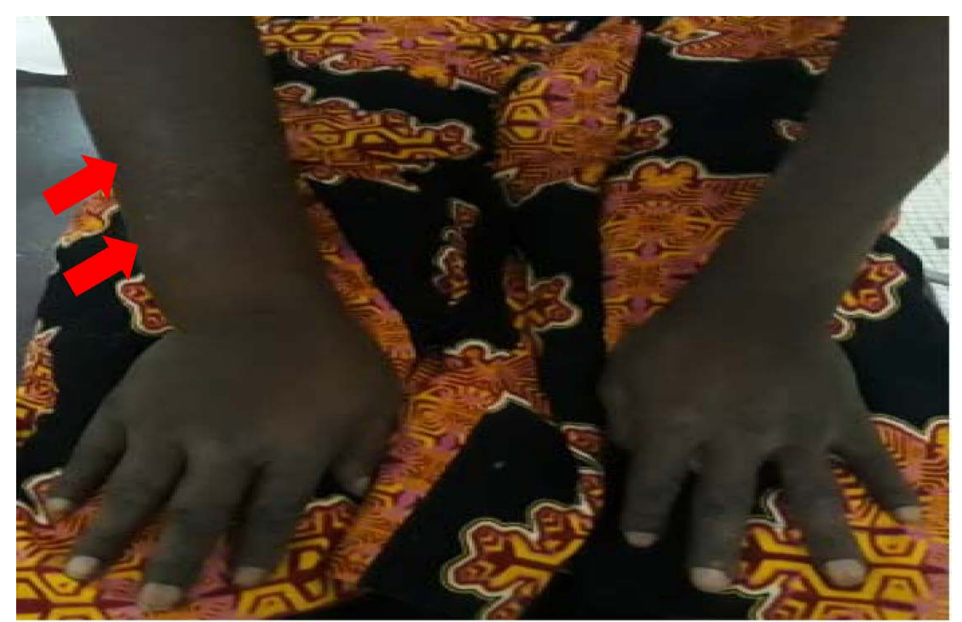

Figure 2. Edema of the distal part of the right upper limb (arrows).

Table 2. Characteristics of patients.

\begin{tabular}{|c|c|c|c|}
\hline Observation Number & 4 & 5 & 6 \\
\hline Age (years)/sex & $38 / \mathrm{F}$ & $39 / \mathrm{F}$ & $25 / \mathrm{M}$ \\
\hline Past medical history/field & Peripartum cardiomyopathy & $\begin{array}{l}\text { Early spontaneous abortion } \\
\text { Uterine fibroid }\end{array}$ & Nothing \\
\hline Clinical signs & $\begin{array}{l}\text { Painful edema } \\
\text { Paresthesia } \\
\text { Heaviness }\end{array}$ & $\begin{array}{c}\text { Painful edema } \\
\text { Turgor of the jugular vein indurated } \\
\text { Fever } \\
\text { Collateral venous circulation }\end{array}$ & Painful edema \\
\hline Location & Jugular, subclavian, axillary, brachial & Jugular, subclavian, axillary, brachial & Subclavian, brachiocephalic \\
\hline Etiologies & Thrombophilia assessment not carried & $\begin{array}{c}\text { Thrombophilia assessment not carried } \\
\text { HIV serology (-) } \\
\text { Abdominopelvic ultrasound (-) } \\
\text { Mammography (-) }\end{array}$ & $\begin{array}{c}\text { Thrombophilia assessment (-) } \\
\text { HIV serology (-) }\end{array}$ \\
\hline Treatment/duration & $\begin{array}{c}\text { LMWH + VKA + } \\
\text { compression/current }\end{array}$ & LMWH + VKA + compression/6 months & $\begin{array}{l}\text { LMWH + VKA + } \\
\text { compression/6months }\end{array}$ \\
\hline Evolution & $\begin{array}{l}\text { (1 month) Edema of the hand and } \\
\text { forearm }\end{array}$ & $\begin{array}{c}\text { (10 months ) Post-thrombotic syndrome. } \\
\text { Stop of professional activity }\end{array}$ & (1 year) Good \\
\hline
\end{tabular}

LMWH: low molecular weight heparin; VKA: vitamin K antagonists; (-): normal; HIV: Human Immunodeficiency Virus; F: Female; M: Male. 


\section{Observation 5}

Ms. A. T, 39, dressmaker (knitting, beading), right-handed, had consulted for neck pain and swelling of the left upper limb. The history reported the onset, 5 6 days before admission, of very intense left neck pain radiating to the upper limb, associated with headache. There followed 3 days later, in a febrile context, the appearance of edema extending to the whole limb associated with relative functional impotence. In these antecedents, there was a follow-up in gynecology for a uterine fibroid and an early spontaneous abortion. The examination showed an edematous and painful limb, the presence of collateral venous circulation, a turgor of the jugular vein indurated, and clinical anemia. The heart rate was at 104 beats per minute and the temperature at $37.9^{\circ} \mathrm{C}$. Biology found a microcytic hypochromic anemia and a negative retroviral serology. Doppler ultrasound showed a venous thrombosis extended to the jugular, subclavian, axillary, cephalic and basilic veins. The chest CT-scan found no signs of a pulmonary embolism. The thrombophilia assessment had not been carried out. The abdominopelvic ultrasound found a polymyomatous uterus and the Pap smear and mammography were normal. She had benefited from LMWH treatment with an overlapping curative dose, then relayed by VKA (acenocoumarol) and associated with venous compression (Table 1). A control at 10 months found a slight edema in the proximal part of the arm (a difference of $04 \mathrm{~cm}$ ) and a collateral venous circulation (Figure 3). The presence of a paraesthesia and a heaviness with the effort had motivated a break of her professional activity.

\section{Observation 6}

Mr P. F, 25, student, was received for painful edema of the dominant thoracic limb. Symptoms started 3 days before admission with heaviness of the limb, no notion of trauma, followed a few hours later by a progressive increase in volume and pain of stronger intensity. The interrogation found no personal or family history of thromboembolic disease and he did not practice any sport. The examination found an enlarged limb with edematous volume from the root of the shoulder to the bend of the elbow, increased local heat and pain on palpation and mobilization of the limb. The rest of the exam was normal.
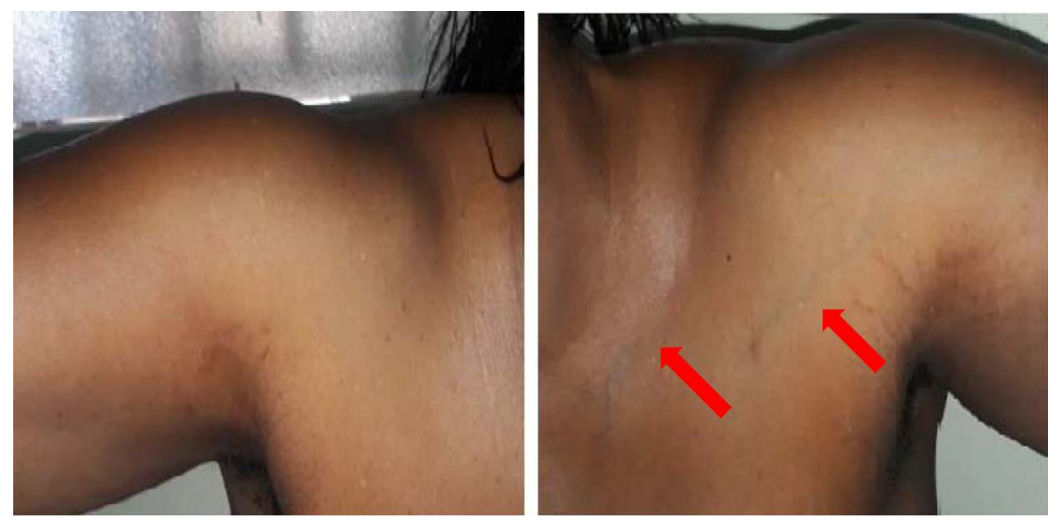

Figure 3. Discreet asymmetry of the limb and presence of collateral venous circulation at the shoulder (arrows). 
The venous Doppler ultrasound had revealed a thrombosis of recent appearance of the subclavian with head of the thrombosis localized at the level of the brachio-cephalic confluence without invasion of the superior vena cava or the jugular (Table 2).

The patient was put, during hospitalization, on LMWH with an overlapping curative dose, then relayed by VKA (acenocoumarol). He also had venous compression.

The outcome was favorable for stopping treatment at 6 months, with complete regression of the edema. At the one-year follow-up, the patient had not presented a recurrence or post-thrombotic syndrome.

\section{Discussion}

Upper limb DVT affected young adults in our work, with an average age of 27.6 years, as found in the literature with a median age between 30 - 35 years [5]. However, our patients were younger than those in the literature [3] [4] [6]. DVT of the upper limb can occur at any age; the age of onset depends on the etiology.

The predominance of women in our study was observed by Mustafa and Co. and Codjo and Co. [4] [7]. The small size of our population does not allow us to conclude, on any predisposition of the female sex, a risk of DVT of the thoracic limb.

The clinical signs of inflammation were the most common signs seen in our study. Pain was present in five (05) of our patients, Marie and Co. found $81.6 \%$ [6] and Codjo and Co, 100\% [4]. Edema was noticed in all our patients. Other manifestations were noticed, such as heaviness (present in one of our patients) or limb tension which were relieved by elevation, axillary or cervical pain, paresthesia of the limb, secondary to irritation of the brachial plexus [8].

The diagnosis of venous thrombosis of the upper limb is primarily clinical. As with the lower limb, the clinical signs of thrombosis of the upper limb are related to the obstruction and the resulting inflammation. The venous Doppler ultrasound allowed the diagnosis to be made in all of our patients. It specified the location and extent of the thrombosis. It is the first-line diagnostic method in the vast majority of cases [9]. In the absence of thrombosis, it authenticates a stasis, localizes an extrinsic compression and directs towards other differential diagnoses (compressive hematoma or muscular compartment) [10]. Phlebography should be reserved in case the ultrasound is negative or difficult with a high degree of suspicion [11].

In our work, no risk factor was found. DVT of the upper limb was primary in three (03) patients. One of the patients was a dressmaker (knitting, beading) and the other two were pupil and student. Primary upper limb DVT is a very heterogeneous category and includes both exercise-induced DVT and idiopathic DVT. Primary DVT requires a rigorous physical examination, in particular the performance of dynamic maneuvers (syndrome of the parade) and the exhaustive search for coagulation abnormalities. In the absence of a standardized defi- 
nition of effort considered as intense, the allocation of patients to one or the other of these two groups is sometimes arbitrary [8]. Intense sporting activity is not always necessary. Sanson and Co. [12] reported a case of venous thrombosis associated with the daily wearing of a backpack and a profession of the patient related to that of a fastfood cook [13].

In three (03) patients, DVT occurred in a field at increased risk of thrombosis: homozygous sickle cell anemia and peripartum cardiomyopathy.

DVT of the secondary upper limb is the most frequent, i.e. two thirds of the cases, linked to intravenous devices and cancers [3]. No case of thrombosis linked to a central venous catheter had been found. Kane and Co reported two (02) cases of DVT on pace maker [3]. For patients with intravenous devices, a large number of DVTs of the upper limb go unnoticed in the acute phase [14]. If a routine ultrasound was performed, almost a quarter of patients with pacemakers would be diagnosed with DVT, while the symptomatic upper limb DVT rate is only $2 \%$ [15].

Heparin therapy relayed by VKA (acenocoumarol) was the most often used treatment protocol. One patient had received VKA treatment directly. The duration of treatment was of 6 months in all patients. It is specified that the protocol for determining this duration must be "similar" to that for deep vein thrombosis of the lower limb [10]. The duration of anticoagulation is not the subject of a universal consensus; conventionally, a treatment period of at least three months should be recommended. Thereafter, treatment may be discontinued if a transient promoting factor is found. Conversely, an extended period of at least one year is the rule in the presence of a permanent promoting factor, or if DVT is considered to be idiopathic [16]. All of our patients received venous compression. The effect of this compression on the occurrence of post-thrombotic syndrome is not proven [17].

In our work, there was no case of pulmonary embolism. DVT of the upper limb has long been considered a mild condition. The risk of PE is certainly lower than in the case of DVT of the lower limb but remains clinically significant. It is $5 \%$ of symptomatic embolism [17].

On the other hand, the occurrence of post thrombotic syndrome is very high (in 20\% of cases [12]). One of our female patients had post thrombotic syndrome with cessation of professional activity. These complications are favored by the proximal nature of DVT [12].

A recurrence at 5 years is reported in $8 \%$ of the cases [18].

\section{Conclusion}

Data on upper limb deep vein thrombosis are limited. The profile of our patients is different from the rare cases published. The etiology approach is a real challenge for appropriate care. Multicentric work is necessary to better understand the profile of patients with venous thrombosis of the upper limb in Sub-Saharan Africa. 


\section{Conflicts of Interest}

The authors declare no conflicts of interest regarding the publication of this paper.

\section{References}

[1] Isma, N., Svensson, P.J., Gottsater, A., et al. (2010) Upper Limb Deep Venous Thrombosis in the Population-Based Malmo Thrombophilia Study (MATS). Epidemiology, Risk Factors, Recurrence risk, and Mortality. Thrombosis Research, 125, e335-e338. https://doi.org/10.1016/j.thromres.2010.03.005

[2] Joffe, H.V., Kucher, N., Tapson, V.F., et al. (2004) Upper Limb Deep Vein Thrombosis: A Prospective Registry of 592 Patients. Circulation, 110, 1605-1611. https://doi.org/10.1161/01.CIR.0000142289.94369.D7

[3] Kane, A.D., Ndiaye, M.B., Diao, M., et al. (2011) TVP des membres supérieurs sur pacemaker: À propos de deux cas. Angéiologie, 63, 61-63.

[4] Codjo, L., Mawupe, J., Hounkponou, M., et al. (2018) Les thromboses veineuses profondes des membres thoraciques chez le sujet noir africain: À propos de 5 cas observés à l'USERC du CNHU-HKM de Cotonou. Pan African Medical Journal, 29, 113. https://doi.org/10.11604/pamj.2018.29.113.11999

[5] Martinelli, I., Battaglioli, T., Bucciarelli, P., et al. (2004) Risk Factors and Recurrence Rate of Primary Deep Vein Thrombosis of the Upper Limbs. Circulation, 110, 566-570. https://doi.org/10.1161/01.CIR.0000137123.55051.9B

[6] Marie, I., Lévesque, H., Cailleux, N., et al. (1998) Les thromboses veineuses profondes des membres supérieurs: À propos de 49 cas. La Revue de Médecine Interne, 19, 399-408. https://doi.org/10.1016/S0248-8663(98)80864-3

[7] Mustafa, S., Stein, P.D., Patel, K.C., et al. (2003) Upper Limb Deep Venous Thrombosis. Chest, 123, 1953-1956. https://doi.org/10.1378/chest.123.6.1953

[8] Robert-Ebadi, H., Becker, F. and Righini, M. (2015) Thrombose veineuse profonde du membre supérieur: Une forme particulière de maladie thromboembolique veineuse. Revue Médicale Suisse, 11, 342-347.

[9] Baxter, G.M., Kincaid, W., Jeffrey, R.F., et al. (1991) Comparison of Colour Doppler Ultrasound with Venography in the Diagnosis of Axillary and Subclavian Vein Thrombosis. British Journal of Radiology, 64, 777-781. https://doi.org/10.1259/0007-1285-64-765-777

[10] Connault, J. and Pistorius, M.A. (2006) Les thromboses veineuses du membre supérieur. Sang Thrombose Vaisseaux, 18, 385-389.

[11] Fraser, J.D. and Anderson, D.R. (1999) Deep Venous Thrombosis: Recent Advances and Optimal Investigation with US. Radiology, 211, 9-24. https://doi.org/10.1148/radiology.211.1.r99ap459

[12] Sanson, H., Gautier, V., Standal, A., et al. (2016) Thrombose veineuse profonde du membre supérieur chez une violoniste: Le syndrome de l'archer. Journal des Maladies Vasculaires, 41, 396-402. https://doi.org/10.1016/j.jmv.2016.10.004

[13] Ayteken, E., Edogan, Y.P., Okur, S.C., et al. (2015) Differential Diagnosis of a Rare Case of Upper Limb Pain: Paget-Schroetter Syndrome in a Doner Kebab Chef. The Journal of Physical Therapy Science, 27, 3333-3335. https://doi.org/10.1589/jpts.27.3333

[14] Lacroix, P. (2015) La maladie thrombo-embolique veineuse. Elsevier-Masson, Amsterdam, 328 p. https://doi.org/10.1016/S1773-035X(15)30153-2 
[15] Van Rooden, C.J., Molhoek, S.G., Rosendaal, F.R., et al. (2004) Incidence and Risk Factors of Early Venous Thrombosis Associated with Permanent Pacemaker Leads. Journal of Cardiovascular Electrophysiology, 15, 1258-1262. https://doi.org/10.1046/j.1540-8167.2004.04081.x

[16] Benhamou, Y., Marie, I., David, N., et al. (2011) Les thromboses veineuses profondes des membres supérieurs. La Revue de Médecine Interne, 32, 567-574. https://doi.org/10.1016/j.revmed.2010.08.007

[17] Kearon, C., Akl, E.A., Comerota, A.J., et al. (2012) Antithrombotic Therapy for VTE Disease: Antithrombotic Therapy and Prevention of Thrombosis (9th Edition): American College of Chest Physicians Evidence-Based Clinical Practice Guidelines. Chest, 141, e419S-e496S. https://doi.org/10.1378/chest.141.5.1369b

[18] Mai, C. and Hunt, D. (2011) Upper-Limb Deep Venous Thrombosis: A Review. The American Journal of Medicine, 124, 402-407.

https://doi.org/10.1016/j.amjmed.2010.11.022 